\title{
Home Care Reform in the Netherlands: Impacts on Unpaid Care in Rotterdam
}

\author{
Irene van Staveren
}

Published online: 7 April 2009

(C) Association for Social Economics 2009

\begin{abstract}
The 2007 change in the law of home care for household help in the Netherlands concerns competitive tendering at municipal level. This has reduced quality and choice for care receivers. In this paper, I report from a small survey in the city of Rotterdam on the impact of the law change on unpaid home carers. The results show that the burden for unpaid carers has increased whereas the quality of paid care as perceived by the unpaid carers has declined. This calls into question whether the reform has met its objectives: improving participation of people with needs for household help and improving efficiency in service delivery.
\end{abstract}

Keywords Home care $\cdot$ Netherlands $\cdot$ Unpaid care $\cdot$ Competitive tendering

\section{Introduction}

In the Netherlands, out of 16 million inhabitants half a million people make use of formal home care. Until 1 January 2007, Dutch home care provisioning used to be supplied by relatively small, profit and non-profit home care organizations. Home care was financed through national level social insurance and allocated at the national level through local home care providers. The majority of home care organizations catered for only one town or region, and only since a few years, some organizations have merged, within and across regions, in a strategic move to prepare for the 2007 market liberalization policy. The demand for home care has increased steadily over the past years, largely due to the aging population, while increased demand is also due to a steady increase in female labour force participation, which puts pressure on the availability of unpaid home care ${ }^{1}$. Nevertheless, the level of

\footnotetext{
${ }^{1}$ According to a European comparative study by Francesca Bettio and Janneke Plantenga, 15 percent of Dutch women do not participate in the labour force because of caring responsibilities, while 11 percent of working women work part-time because of caring responsibilities (Bettio and Plantenga 2004, Figure 7).

I. van Staveren $(\bowtie)$

ISS, PO Box 29776, 2502 LT The Hague, The Netherlands

e-mail: staveren@iss.nl
} 
unpaid care is very high in the Netherlands, compared with other European countries, as Bettio and Plantenga (2004) have shown with their care index for European countries. The increased demand for home care has resulted in waiting lists for home care already since the 1990s.

Since the first of January 2007, a new social support law, the $\mathrm{WMO}^{2}$, has been implemented which includes a structural reform of the household services of home care in its supply, organization, and financing, towards more market liberalization. The WMO has created a split in home care services between personal care and care for the household: whereas personal care still belongs to the national level responsibility, care for the household is now delegated to municipalities. This paper will concentrate on care for the household within home care $^{3}$. Home care in this narrow sense includes tasks such as cleaning, doing grocery shopping, preparing meals, washing clothes and washing dishes (level one) and at the organizational level, help with the organization of the household or help with preparing meals (level two). The objective of the WMO is to support the social participation of all citizens. For the home care sector, this objective implies that everyone is entitled to home care services at an affordable rate and at least the same level of quality as before 2007, within a reasonable period of time. A secondary objective is to make the home care sector more efficient, with the expectation that market liberalization will end waiting lists, reduce costs, and improve quality of care.

A major characteristic of this home care reform is decentralization towards municipalities. One year after its implementation, complaints by clients, suppliers, care workers and parliamentarians have led the Ministry of Health to revise the law in two ways in order to counteract strategic behavior by home care organizations following the 2007 change of law ${ }^{4}$. The first revision implies that home care organizations are no longer allowed to supply home care through contracted services by workers who have no labour contract and for which, as a consequence, the client should take employer's responsibility. This revision eliminates unwanted employer risk for clients who prefer to receive home care in natura, and also helps to stop the tendency by home care organizations to substitute employees by flex workers without labour contract. The second change entails the requirement that home care organizations should indicate in their tenders how they would provide job opportunities for employees of home care organizations that do not gain a contract in the competitive tender process at municipal level. This second revision seeks to protect home care workers' jobs and prevent a shift of care workers to other sectors

\footnotetext{
${ }^{2}$ WMO is the acronym for the Wet Maatschappelijke Ondersteuning, or social support law, which includes a variety of forms of social support of which household care as part of home care is the largest part, also in financial terms.

${ }^{3}$ Henceforth, 'home care' in this paper will refer to the household care part of home care services. According to a study using a survey carried out at the end of the $1990 \mathrm{~s}$, about $25 \%$ of all home care receivers received only household care, most others a combination of home care services including household care (van Campen and Woittiez 2003).

${ }^{4}$ See letter by the government 15-02-2008 'Wijziging WMO: versterking positie client in WMO'.
} 
of the labour market, which would imply a loss of human capital for the home care sector.

\section{The Dutch Home Care Reform}

The 2007 reform is the latest step in market liberalization of the Dutch home care sector - at least, the household care part of home care. The core of the reform is decentralization combined with competitive tendering. This has made municipal governments responsible for the following three tasks:

1) Creation of a competitive market through a (European) tender process; the municipality awards contracts to the most competitive suppliers and selects at least 3 suppliers per municipality for providing home care in natura.

2) Arrange for the decision making on the allocation of care per client through a municipal or regional assessment agency.

3) Allocate individual budgets to clients or allocate resources per client to home care providers from a municipal budget, through the intermediary of care agencies.

4) Monitor the quality of home care in relation to the objective of the WMO to guarantee participation in society for everyone.

One of the most striking results of the Dutch home care reform in just one year time is that the market has resulted in a much stronger cost reduction than was expected. The municipalities were given a total amount of roughly 1 billion euro for 2007. This budget was the same as it was at central level in 2006, which in turn had not changed since 2005, whereas estimates are that demand had increased 10\% between 2005 and 2006 (SP 2007). Now it appears that the municipalities have spent only 800 million euro of the budget (Volkskrant 13/02/08) ${ }^{5}$, making a saving of $20 \%$. Under the pressure of fierce competition, home care organizations have offered their services well below the prices of previous years (on average 12\% which in some cases even implies reductions up to $30 \%$ according to FAOT 2007) while some organizations have admitted that they offered prices below the cost price. A number of large home care organizations are currently under threat of bankruptcy, including the two major ones in Amsterdam and Rotterdam.

The provisioning of home care is means tested at the household level. This implies that clients are required to pay a contribution, depending on their own and partner's income. Also the personal budget, or PGB, is means-tested. The contribution to be paid from one's own income has increased considerably in 2007. This is caused by the WMO's equalizing of budgets for people who receive care in natura (from a home care organization) and those who receive care through a PGB (hiring a relative or anyone else they prefer) (Volkskrant, 16/01/08). This particularly hits those with higher incomes, but even for those with an average (mode) income (30,000 euro gross annual income) less than $3 \mathrm{hrs}$ home care through PGB is just as expensive as hiring a domestic help on the market without a PGB.

\footnotetext{
5 The Ministry of Health is analyzing what has happened to the other 200 million euro.
} 


\section{Overview of Relevant Literature}

An important part of home care is informal care by relatives, friends and neighbors. A couple of studies have analyzed the impact of home care reform on the substitution between formal (paid) home care and unpaid home care. Bolin et al. 2007). It did find, however, that the more generous formal home care services allowed single elderly persons to live at home for a longer period of time.

In the Netherlands, unpaid home carers tend to provide four times as much care as paid home care in the Netherlands (Schadé and Dokter 1995). Also here, substitution effects have been found as well as complementarity (Mur-Veenman et al. 1993). In a study on the allocation of home care over the 1992-1996 period, using a large sample of clients $(n=7732)$, researchers found that in 42 percent of the cases, unpaid care was provided alongside paid home care (van Campen and Woittiez 2003). According to a detailed study for the year 2001, unpaid care appears to provide complementary care to paid home care, as measured by a significant gap between demand and supply of home care (Algera 2005). In particular, for two thirds of chronically ill clients, there is a gap between their self-expressed needs for home care and the quantity and quality of paid home care received. At the same time, unpaid care also substitutes for formal care. The same study shows that there is also a gap between the needs assessment and the care actually delivered to clients. One third of chronically ill clients receive less formal home care than they are entitled to according to the formal needs assessment, implying that home care organizations do not provide the necessary hours and/or quality or types of home care in accordance with the independent needs assessment (idem).

The city of Rotterdam pays attention in its WMO policy 2008-2010 to unpaid home care (Gemeente Rotterdam 2007). This document mentions an estimation of the economic value of unpaid home care in Rotterdam of 1 billion euro per year, calculated by multiplying the time spent by the average 60,000 carers in the city with the lowest home care rate for paid household help (idem, p. 6 and p. 15). In order to support unpaid carers, Rotterdam has set up 13 support centers, which are, however, only in contact with a total of 1200 carers, which is $5 \%$ of all estimated unpaid carers in the city. The problem is indeed how to reach these people whose work is so invisible. Concrete policy measures still have to be worked out but are envisaged to consist of the following measures (idem, pp. 22-23):

- quick respite care

- $\quad$ supply of domotica (ICT appliances) and home adjustments

- aids for daily care

- courses to reduce physical burdens in home care tasks

- shopping help

- extra child care

- administrative help

- free parking

- (electronic) contact groups

- after care for unpaid care givers when the person they care for has died or moved to institutional care

- connection to an electronic network of voluntary home carers 


\section{Unpaid Home Care in Rotterdam: A Small Preliminary Survey}

None of the recent partial evaluation reports on the 2007 home care reform has paid much attention to possible negative impacts on unpaid home care by family members, neighbors, friends, and volunteers. This section of the paper therefore reports of a survey which I have carried out in Rotterdam, the country's second largest city. The municipality's policy paper justifies its policy not only because it fits well with the WMO but also because research had shown that in Rotterdam there is a relatively large group of unpaid home carers who indicate that they experience their care giving task as very hard. 1800 unpaid home carers have indicated to feel overburdened while 4500 have indicated that they feel heavily burdened with their unpaid home care task (Gemeente Rotterdam 2007: 9). Another reason for selecting Rotterdam is that the traditionally largest home care organization, with an $85 \%$ market share, was not awarded a contract in 2007.

Of the 150 surveys sent out, only 46 came back, of which 39 were usable. $42 \%$ report that the person they care for also receives paid home care. In $45 \%$ of the cases the unpaid home carer and person cared for are part of the same household, while in most of the cases the person cared for is the partner. The average age of the person cared for is 69 , whereas the average age of the unpaid home carer is $65.80 \%$ of the unpaid home carers are women; $56 \%$ were pensioners, while $15 \%$ earned an income of their own; $95 \%$ of the unpaid home carers started their unpaid home care already before 2007.

Concerning the policy change of 2007, several questions were asked about changes in paid home care and unpaid home care: 33\% report that paid home care hours have increased over the past year, 10\% say that hours of paid care have decreased, whereas $57 \%$ say that paid hours have remained the same. Those who report that hours of paid home care has increased all say that this was after a new needs assessment. For those cared for who do not receive any paid home care, there is a variety of reasons why this is not the case: zero allocation in the need assessment because of a judged lack of need or the presence of sufficient unpaid care, or care receivers found arranging a PGB too complicated so they rather have unpaid care than care by the same person paid by the municipality, whereas most report they do not know why the person they care for does not receive paid home care.

The tasks of unpaid home carers are diverse and most of them carry out more than one task, the average number of tasks per unpaid home carer is 4.7 unpaid home carers even do 7, 8 or 9 tasks. Interestingly, 4 out of these 7 indicated that the person they care for does also receive paid home care. Apparently, paid home care is too limited in relation to the care burden of the unpaid home carer. Figure 1 below shows the frequency of tasks mentioned by 35 unpaid home carers. The diagram shows that the most common tasks are help with administration, functional support, household help, personal care, and transport.

The next diagram shows the time use per task for unpaid home carers (Fig. 2). As expected, staying with the person cared for is the most time consuming activity, with an average of 54 hours per week per unpaid home carer. Household help takes up on average 12 hours per week and 20 unpaid home carers indicate that they do household tasks. Out of these 20,60\% of unpaid home carers do household help whereas there is also paid home care, that is, paid household care provided by a 


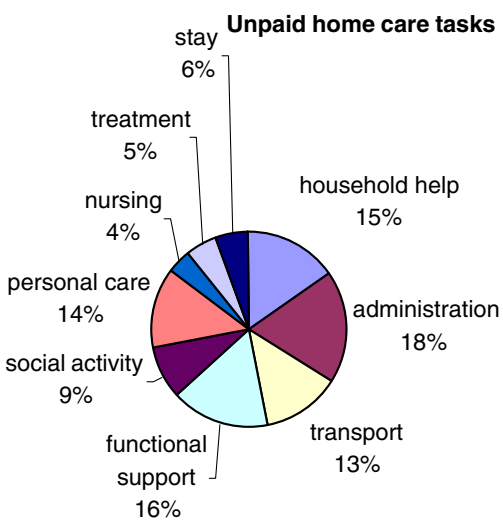

\begin{tabular}{|l|}
\hline$\square$ household help \\
$\square$ administration \\
$\square$ transport \\
$\square$ functional support \\
$\square$ social activity \\
$\square$ personal care \\
$\square$ nursing \\
$\square$ treatment \\
$\square$ stay
\end{tabular}

Fig. 1

home care organization or an individual hired through a personal budget. Apparently, the household help provided by the municipality is not deemed adequate. The average time use across tasks is 44 hours per unpaid home carer per week, which is more than a Dutch fulltime paid working week. One third of unpaid home carers indicate that their time use has increased since the WMO, with an average time increase of 1.5 hours. The tasks which are most often mentioned as requiring more time are household care, functional support and personal care.

The increase in household care may be related to the change since the WMO from more skilled to lower skilled household help by home care organizations, which is a cheaper category of household care. The increased unpaid personal care may be related to the disconnection since the WMO in the financing of personal care still financed at national level and not made competitive - and decentralized household care. It his no longer possible for unpaid home carers and those who they care for to decide on shifts between the two categories within the same budget. An

Time use per task

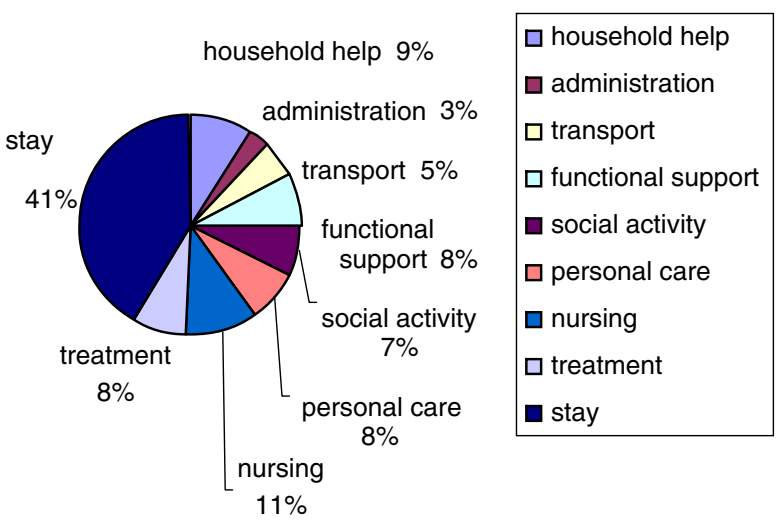

Fig. 2 
implication is that those unpaid home carers who left personal care, such as bathing, to a professional and did other tasks such as household care, have to take up personal care tasks when the care allocation is now only for household tasks and no longer for personal care. Not all care receivers and unpaid home carers like the idea of bathing someone when the relationship is between parent (care receiver) and child (care giver), for example. Hence, choice has been reduced here.

On the changes of the WMO on the burden of unpaid home care, $50 \%$ unpaid home carers state that their caring task has become heavier. Two reasons were mentioned most often (each seven times) for the heavier unpaid care burden: when the care receiver's condition deteriorates, the municipality does not allocate more household help, or more of other forms of home care. For the unpaid home carer, the unpaid care burden results in various limitations. Figure 3 below gives an overview of these. The diagram shows that leisure and social contacts suffer most, but also hobbies, care for one's own household as well as sufficient hours of sleep are affected by the increased unpaid care burden. Overall, half of the respondents state that these limitations have become stronger since the WMO.

The tentative conclusions that can be drawn from the preliminary survey, keeping in mind the small sample size, is that irrespective of whether a care receiver receives paid home care, the burden of unpaid care givers seems high, on average more than 40 hours per week. The unpaid care burden seems to have increased since the WMO, although not so much in hours per week (1.5) but more so in complexity and heaviness of burdens. The split between household home care and other forms of care such as personal care has reduced choice, because shifts in these tasks between paid and unpaid home carers are no longer possible. Although the WMO concerns the household care part of home care, unpaid care givers still often do household care, which may have become heavier due to a shift in care providers from higher to lower skilled workers, which in turn is a likely result of the fierce competition for contracts with municipalities. The increased burden of unpaid carers also is paralleled by stronger limitations for other activities, in particular for leisure and social contacts.
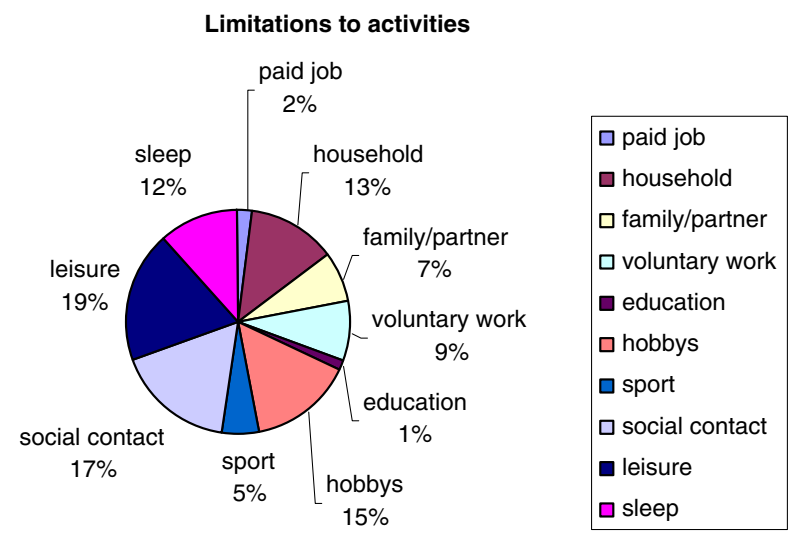

Fig. 3 


\section{Conclusions}

The literature review and small survey suggest a few negative impacts of Dutch competitive tendering in home care. First, it did save money and did not reduce access, but it is unclear how the $20 \%$ budget saving has been spent and whether it has been spent on meeting the purposes of the WMO law at all. Second, the competitive tendering seems to have resulted in lower quality of services due to less skilled and more flexible labour, while the costs for those clients on a personal budget have increased. Third, client choice seems to have reduced due to the impossibility to substitute between paid and unpaid care between categories of home care, such as household care and personal care, and due to the pressure by home care organizations to use a personal budget, with subsequent employer risk, rather than home care in natura. Fourth, the recent adaptations to the law to prevent suppliers to force non-contract workers on clients and to force suppliers to take up workers of organizations that lost a contract are likely to bring the offered prices back to the original sectoral average, eliminating the price reduction of the competitive process. The question that arises whether there was much inefficiency in home care production in the first place and if there was, whether it was in wage cost or perhaps somewhere else, such as in home care management and organizational costs, assessment procedures, and the bureaucratic resource transfer mechanism. Moreover, the competitive tendering procedure has increased marketing costs as well as the administrative costs for participating in tendering procedures for home care suppliers. Finally, it seems that there are direct consequences of the reduced quality and choice for clients on unpaid home carers: they indicate that their burden has become heavier, even when the persons they care for receive paid household home care and receive increased hours of help when they are re-assessed after a deterioration of their condition. This does not only call for a good unpaid home care policy, as the city of Rotterdam is for example developing, but also for a rethinking of the paid home care reform, as it now seems that the enormous and unexpected 'efficiency gain' was in fact mostly a quality reduction based on reducing labour cost, with a negative impact both on paid and on unpaid carers.

\section{References}

Algera, Marco (2005) All You Need Is ... Home Care. Matches Between Home Care Needed, Indicated and Delivered. A Study Among Chronic Patients. PhD Dissertation, University of Maastricht. Available from www.nivel.nl/

Bettio, F., \& Plantenga, J. (2004). Comparing Care Regimes in Europe. Feminist Economics, 10(1), 85113.

Bolin, A., Lindgren, B., \& Lundborg, P. (2007). Informal and Formal Care Among Single-Living Elderly in Europe. Tinbergen Institute Discussion Paper 2007-31/3. Amsterdam/Rotterdam: Tinbergen Institute.

van Campen, C., \& Woittiez, I. B. (2003). 'Client Demands and the Allocation of Home care in the Netherlands. A Multinomial Logit Model of Client Types, Care Needs and Referrals'. Health Policy, 64, 229-241.

FAOT. (2007). 'De Wet maatschappelijke ondersteuning en de arbeidsmarkt van de thuiszorg. Eindrapport'. FAOT: Den Haag.

Gemeente Rotterdam (2007) Meer Rotterdammers zorgen voor elkaar. Beleidskader intensivering ondersteuning unpaid home carers 2007-2010. Rotterdam. 
Mur-Veenman, I., van Raak, A., \& Maarse, H. (1993). Dutch Home Care: Towards a New Organisation? Health Policy, 27, 141-156.

Pezzin, L., Kemper, P., \& Reschovsky, J. (1996). Does publicly provided home care substitute for family care? Experimental evidence with endogenous living arrangements. The Journal of Human Resources, 31(3), 650-676.

Schadé, E., \& Dokter, H. A. C. H. (1995). Thuiszorg: tussen idee en werkelijkheid. Nederlands Tijdschrift Geneeskunde, 139(47), 2444-2448.

SP. (2007). WMO in uitvoering. Den Haag: Socialistische Partij.

Stabile, M., Laporte, A., \& Coyte, P. (2006). Household Responses to Public Home Care Programs. Journal of Health Economics, 25, 674-701. 